We present a novel approach to treat complex or difficult mitral leaflet prolapse. It is easily reproducible and based on the simplification of 2 well-established techniques: chordal transfer for treatment of $\mathrm{ALP}^{4}$ and conventional replacement of chordae tendineae with polytetrafluoroethylene sutures. ${ }^{5}$ It alleviates surgical interference with valve components, chordal length manipulation, or annular plication and preserves the natural anatomy and integrity of the mitral valve. The artificial chordae system homogenously fixates the entire prolapsed leaflet at an ideal distance from each of the 2 papillary muscles, thus equilibrating the systolic stress without delicate measurements or complicated knotting of individual artificial chordae. The encouraging results in this short series are to be confirmed with long-term follow-up studies.

\section{References}

1. Braunberger E, Deloche A, Berrebi A, et al. Very long-term results (more than 20 years) of valve repair with Carpentier's techniques in nonrheumatic mitral valve insufficiency. Circulation. 2001;104(suppl I):I-8-11.

2. Iung B, Baron G, Butchart EG, et al. A prospective survey of patients with valvular heart disease in Europe: The Euro Heart Survey on Valvular Heart Disease. Eur Heart J. 2003;24:1231-43.

3. Hayek E, Gring CN, Griffin BP. Mitral valve prolapse. Lancet. 2005; 365:507-18.

4. Lessana A, Scorsin M, Romano M, et al. Transposition of posterior leaflet for treatment of ruptured main chordae of the anterior mitral leaflet. J Thorac Cardiovasc Surg. 1985;89:804-6.

5. David TE. Artificial chordae. Semin Thorac Cardiovasc Surg. 2004;16: 161-8.

\title{
A new surgical technique for ventricular septal rupture closure after myocardial infarction
}

\author{
Luís Roberto Gerola, MD, PhD, Hyong C. Kim, MD, Armindo Pereira Filho, MD, Wesley Araújo, MD, \\ Paulo César Santos, MD, and Enio Buffolo, MD, PhD, São Paulo, Brazil
}

I

n this study we propose a new surgical approach to correct ventricular septal rupture based on juxtaposition of the left and right ventricular free walls of the ruptured region to reinforce patch closure and avoid residual shunt.

\section{Clinical Summary}

From May 2002 through August 2006, 5 patients with diagnoses of myocardial infarction who had ventricular septal ruptures were submitted to surgical treatment with this new surgical approach, 4 with anterior myocardial infarction and 1 with posterior myocardial infarction. Two patients were in cardiogenic shock at the time of the operation, 1 was hemodynamically stable, and the other 2 were in New York Heart Association functional class III with severe pulmonary edema. Other important preoperative data are presented in Table 1.

The condition of the first patient was the motivating factor in the development of this approach. The patient was operated on to close the ventricular septal rupture and presented with a residual

From the Rim Hospital and São Paulo Hospital of the Division of Cardiovascular Surgery of the Federal University of São Paulo, Brazil,

Received for publication March 23, 2007; revisions received May 9, 2007; accepted for publication May 31, 2007.

Address for reprints: Luís Roberto Gerola, $\mathrm{MD}, \mathrm{PhD}$, Rua dos Otonis 880/apto 81 Vila Clementino CEP:04025-002, São Paulo, Brazil (E-mail: gerola@uol.com.br).

J Thorac Cardiovasc Surg 2007;134:1073-6

$0022-5223 / \$ 32.00$

Copyright () 2007 by The American Association for Thoracic Surgery

doi:10.1016/j.jtcvs.2007.05.063 shunt with hemodynamic instability. In the reoperation we performed juxtaposition of the walls because of the great difficulty of this case determined by the intense friability of the septum.

Surgical procedures were done with cardiopulmonary bypass, cold blood antegrade cardioplegia, and topical cooling. After making a left ventriculotomy in the infarcted area and localizing the ventricular septal rupture, a pericardial patch was placed over the rupture region, and sutures were made more distally to reach the normal myocardial wall.

An interrupted suture started on the right ventricular free wall (which was closed) around $1.5 \mathrm{~cm}$ from the anterior interventricular sulcus (or projection of the left anterior descending artery) passing behind the rupture, stitching the pericardial patch in the most inferior portion of septum, and then passing through the base of the anterior papillary muscle of the mitral valve and going to the free wall of the left ventricle, which was also supported with other Teflon bars. We applied 4 to 5 stitches in the same manner.

When these stitches were tied, the free wall of the right ventricle and the free wall of the left ventricle were put close together over the rupture region and over the pericardial patch, closing the ventricular septal rupture by means of juxtaposition of the ventricular free walls over the pericardial patch.

A second line of sutures was executed, stitching the edge of the ventriculotomy and exteriorizing the pericardial patch. In this way we closed the left ventricle with separate stitches supported by Teflon bars. Finally, a running suture with 4-0 Prolene sutures was placed over the ventriculotomy to guarantee good hemostasis.

This technique is characterized by 2 suture lines: one superficial line to close the left ventriculotomy and the superior part of the pericardial patch and another deeper line that juxtaposes the right and left ventricular free walls over the rupture region and pericardial patch (Figures 1 and 2). 
Table 1. Patient characteristics and morbidities

\begin{tabular}{|c|c|c|c|c|c|}
\hline & \multicolumn{5}{|c|}{ Patient no. } \\
\hline & 1 & 2 & 3 & 4 & 5 \\
\hline Male sex & $\mathrm{N}$ & $\mathrm{N}$ & $\mathrm{N}$ & $\mathrm{N}$ & $\mathrm{Y}$ \\
\hline Age (y) & 76 & 68 & 74 & 60 & 62 \\
\hline Hypertension & $\mathrm{Y}$ & $\mathrm{Y}$ & $\mathrm{Y}$ & $\mathrm{Y}$ & $\mathrm{Y}$ \\
\hline Diabetes & $\mathrm{Y}$ & $\mathrm{Y}$ & $\mathrm{N}$ & $\mathrm{Y}$ & $\mathrm{N}$ \\
\hline EF & 0.34 & 0.33 & 0.45 & 0.40 & 0.38 \\
\hline NYHA functional class & IV & IV & III & III & IV \\
\hline Dyslipidemia & $\mathrm{N}$ & $\mathrm{Y}$ & Y & $\mathrm{N}$ & $\mathrm{Y}$ \\
\hline Aortic balloon pump & $Y$ & $\mathrm{Y}$ & $\mathrm{N}$ & $\mathrm{Y}$ & Y \\
\hline Tabagism & $\mathrm{N}$ & $\mathrm{N}$ & $\mathrm{N}$ & $\mathrm{N}$ & $\mathrm{Y}$ \\
\hline $\begin{array}{l}\text { Discharge (postoperative } \\
\text { day) }\end{array}$ & $\begin{array}{l}\mathrm{N} \text { (died 48th } \\
\text { day) }\end{array}$ & Y (30th day) & Y (13th day) & Y (15th day) & $\mathrm{Y}$ (11th day) \\
\hline
\end{tabular}

$E F$, Ejection fraction; NYHA, New York Heart Association; $Y$, yes; $N$, no.

There was 1 death (the first patient) caused by infection complications. This patient had a pulmonary infection and septicemia and died on the 48th postoperative day of multiorgan failure. The other 4 patients made good progress. One of them, who had a kidney transplantation 1 year before and was operated on in cardiogenic shock, stayed for 14 days in the intensive care unit, was discharged on the 30th postoperative day without requiring dialysis, and did not lose the kidney graft. In 4 patients we used an aortic balloon pump in the preoperative period. The rest of the patients stayed in the intensive care unit for 5 to 11 days, and all were discharged around the 15 th postoperative day, were stable

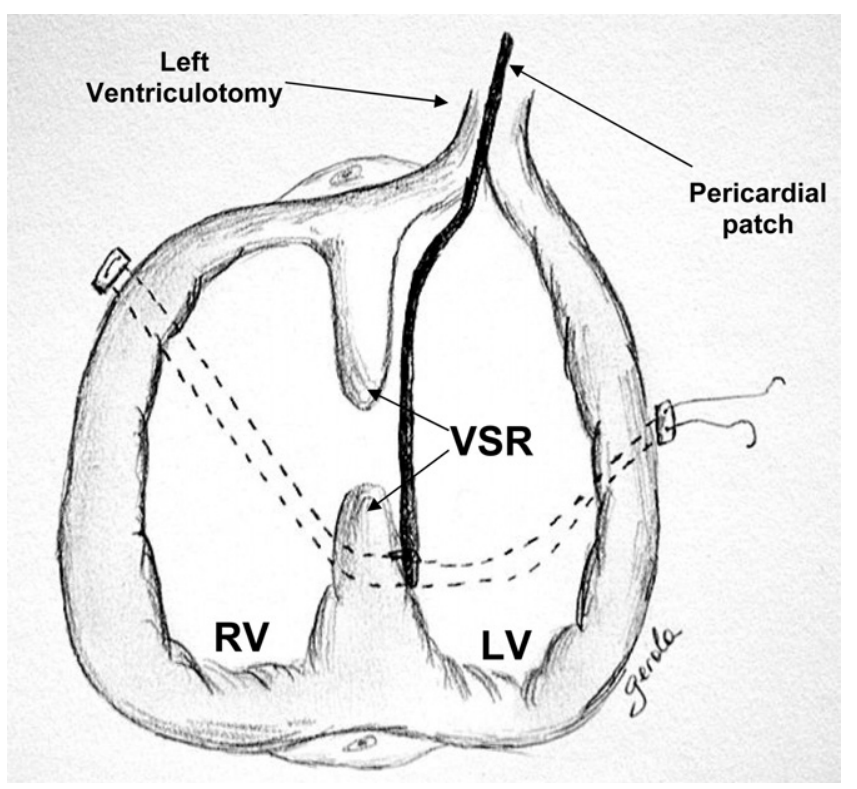

Figure 1. Drawing of a cross-section of the heart showing left ventricle (LV), right ventricle (RV), pericardial patch, left ventriculotomy and ventricular septal rupture (VSR). A stitch from the free wall of the right ventricle passes through the septum and pericardial patch and reaches to the free wall of the left ventricle. hemodynamically, were asymptomatic, and had no other important morbidities and no residual shunt.

Echocardiograms were obtained for all the patients in the postoperative period, which demonstrated the absence of residual shunt. One of them (our second operation) had little blood flow passing between juxtaposed ventricular walls in the direction of the apex. This image was identified by means of echocardiography as a pseudoaneurysm, but in fact, this corresponded to the juxtaposition area (Figures 3 and 4).

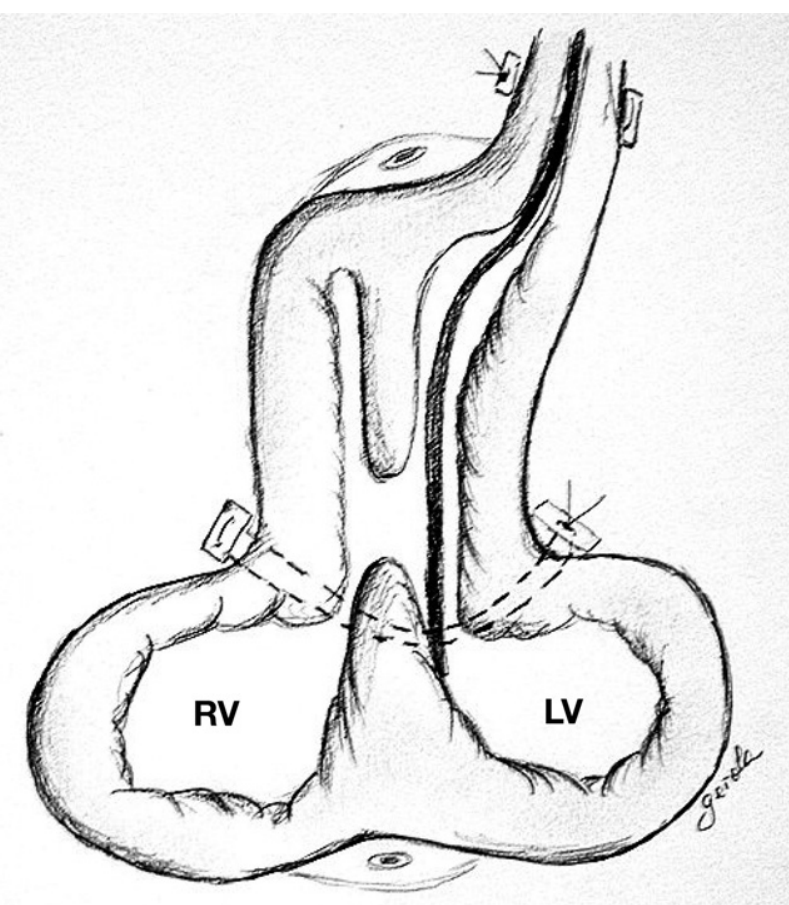

Figure 2. After tying the stitches, there is a juxtaposition of the free wall of the right ventricle and the free wall of the left ventricle over the ventricular septal rupture and the pericardial patch region. $R V$, Right ventricle; $L V$, left ventricle. 

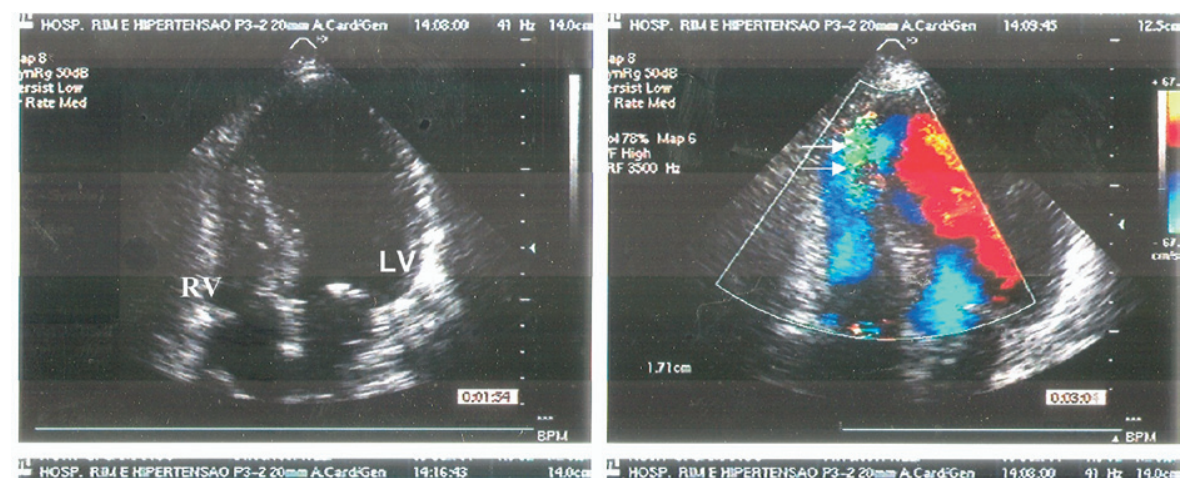

Figure 3. Preoperative echocardiogram showing left ventricular dilatation, place of ruptured ventricular septum, and EF: 0,33 . EF, Ejection fraction.
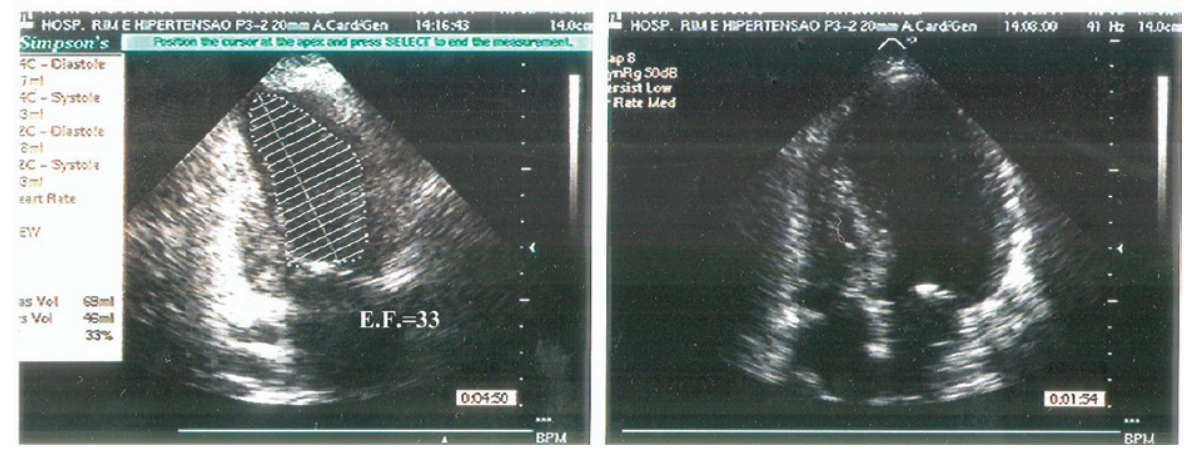

All patients maintained left ventricular dysfunction caused by anterior akinesia. However, recently, we obtained an echocardiogram in the last patient 7 months postoperatively and showed return to normal ventricular function with an ejection fraction of 0.65 , although anterior akinesia was present.

\section{Discussion}

In the present study it was possible to close ventricular septal ruptures in all cases. If we consider only the 4 patients in whom this new approach was applied as the first surgical technique, there was no hospital mortality, and none presented with residual shunt.

Despite the evolution of surgical treatment, we observed heterogeneous surgical results ranging from $10 \%$ to $13.8 \%$ to $38 \%$ in

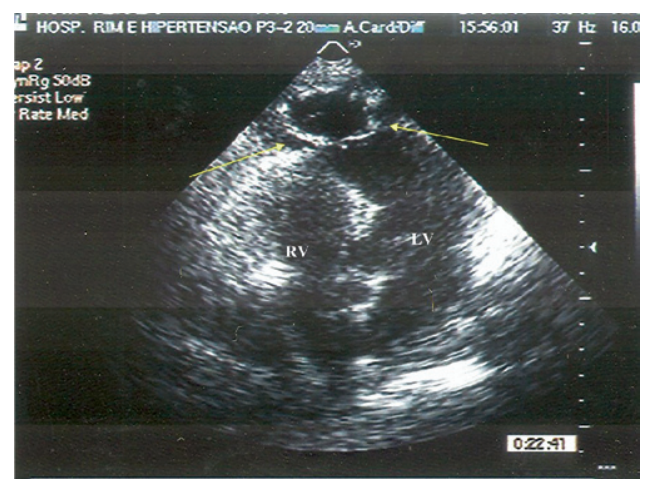

Figure 4. Postoperative echocardiogram showing the area of ventricular juxtaposition of the right and left ventricular wall. In this case, there is a small flow from $L V$ to apex. $L V$, Left ventricle. hospital mortality. ${ }^{1}$ For this reason, looking for a new surgical approach that reduces hospital mortality continues to be a great challenge.

There is a consensus among the majority of the authors that some concepts are very well defined, such as a left ventriculotomy over the infarcted area, the use of a prosthetic patch on the left side of the septum, suturing in noninfarcted myocardial regions, and the absence of resection of the infarcted area. ${ }^{2}$

Another important advance was that of David and colleagues, ${ }^{3}$ when they proposed exclusion of the infarcted area with a pericardial patch, avoiding resection of the infarcted area.

This new proposition represents an additional reinforcement over the patch exclusion. The use of patch exclusion closure of a ventricular septal rupture is the real advance in the treatment of this complication; however, almost all studies indicate a percentage of residual shunt that could represent a future problem. In addition, when there is a great myocardial infarction, extension to support the suture in the noninfarcted area could be difficult, and this juxtaposition of the right and left free walls could represent a good alternative. In fact, it was this situation that we experienced in the reoperation of the first patient. When we had a residual shunt, all tissues were friable, and then we thought of this surgical procedure as the last alternative to resolve this severe surgical problem.

Normally, the infarcted area had dilatation, and this exclusion represents reestablishment of ventricular geometry. Dilatation correction determines benefits over left ventricular function. ${ }^{3}$ The same concept was proposed for the treatment of ventricular aneurysms. ${ }^{4}$

Our proposition goes beyond the closure of the ventricular septal rupture by correcting ventricular dilatation and reducing the 
left ventricle to normal size, during which the reduction of the left ventricular diameter exhibits benefits in recovering left ventricular function in accordance with the concept proposed by Batista. ${ }^{5}$

The possibility of compromise ventricular stroke volume is always present. However, if we consider the base of the papillary muscle as a mark to limit our ventricular reduction, this risk becomes very low, as demonstrated in the echocardiographic results of our latest patient obtained 7 months postoperatively, which present a normal ventricular cavity and normal ventricular ejection fraction.

Although this study involved few patients, this simple technical variation could be used to close the ventricular septal rupture without any residual shunt and could represent one more alternative to resolve a difficult surgical problem.

\section{References}

1. Skillington PD, Lamb RD, Monro JL, et al. Surgical treatment of infarct related ventricular septal defects: improved early results combined with analysis of late functional status. J Thorac Cardiovasc Surg. 1990;99: 798-808.

2. Kitamura S, Mendez A, Kidy JM. Ventricular septal defect following myocardial infarction: experience with surgical repair through a left ventriculotomy and review of literature. J Thorac Cardiovasc Surg. 1971;61:186-99

3. David TE, Dale L, Sun Z. Postinfarction ventricular septal rupture: repair by endocardial patch with infarction exclusion. $J$ Thorac Cardiovasc Surg. 1995;110:1315-22.

4. Jatene AD. Left Ventricular aneurysmectomy: resection or reconstruction. J Thorac Cardiovasc Surg. 1985;89:321-31.

5. Batista R. Partial left ventriculectomy-the Batista procedure. Eur J Cardiothorac Surg. 1999;15(suppl 1):S12-9.

\title{
A case of chest wall angiosarcoma associated with breast implants
}

\author{
Neil D. Saunders, BS, J. Stephen Marshall, MD, and Richard C. Anderson, MD, Peoria, III
}

$\mathrm{P}$ rimary angiosarcomas of the breast or chest wall are exceedingly rare. Generally, primary sarcomas of the breast are less than $0.1 \%$ of breast malignancies, with angiosarcomas making up between $25 \%$ and $40 \%$ of these cases. ${ }^{1}$ Angiosarcomas tend to be aggressive, with a high rate of local recurrence and low 5- and 10-year survival rates. Standard treatment for breast or chest wall angiosarcoma is surgical excision, and there is no clear evidence regarding the role of adjuvant chemotherapy or radiation. ${ }^{2}$ Both irradiation and postmastectomy angioedema are known to substantially increase the risk for angiosarcoma in the breast or chest wall. However, the case we present is primary angiosarcoma in a radiation-naive, augmented breast.

\section{Clinical Summary}

A 58-year-old woman presented with a 4-month history of nonproductive cough and tenderness on the left side of her chest. The patient received bilateral submuscular silicone breast implants in 1975 and had noted that recently the superior aspect of her left breast had become larger than the right. On physical examination, left breast asymmetry was apparent and caused by a firm nonmobile mass. A computed tomographic (CT) scan showed a lobulated

From the Department of Surgery, University of Illinois College of Medicine, Peoria, Peoria, Ill.

Received for publication March 8, 2007; accepted for publication April 23, 2007.

Address for reprints: Neil D. Saunders, 3602 N Kingston Dr, Apt 37, Peoria, IL 61604 (E-mail: neilsaunders@gmail.com).

J Thorac Cardiovasc Surg 2007;134:1076-7

$0022-5223 / \$ 32.00$

Copyright $\odot 2007$ by The American Association for Thoracic Surgery doi:10.1016/j.jtcvs.2007.04.051 mass posterior to her left breast implant measuring $5 \times 4 \mathrm{~cm}$, eroding the third and fourth ribs and extending into the chest (Figure 1). Moderately prominent axillary lymph nodes were also noted. Positron emission tomographic scanning revealed no evidence of spread beyond the anterior left chest wall. Fine-needle aspiration of the mass was pankeratin positive and negative for S100, melanin A, and HMB-45 and was concluded to be nonsmall cell carcinoma.

A wide en bloc excision of the left breast with chest wall and ribs was performed. The tumor was adherent to the pectoralis major and the chest wall (Figure 2). The pectoralis major was removed from the shoulder and clavicle, and the ribs were divided at the sternum. Axillary lymph nodes were removed as well, and the chest wall was reconstructed with a polytetrafluoroethylene* patch. Surgical pathology revealed an epithelioid angiosarcoma staining positive for vimentin, Factor VIII, pankeratin antibody, and CD34. Margins were negative, and no penetration of the pleural space was seen. All 15 of the removed axillary lymph nodes were also negative for primary or metastatic malignancy. The patient did well after the operation and was discharged with a good prognosis.

Five months later, the patient presented with severe anemia and hemoptysis caused by bilateral recurrence of the angiosarcoma. CT of the thorax revealed a $3 \times 3.6-\mathrm{cm}$ mass in the left anterior chest at the level of the aortic arch and bilateral metastatic lung nodules. A left thoracotomy with multiple wedge resection was performed, and the lateral chest wall was further resected. Postoperatively, the patient experienced respiratory failure caused by pneumonia and required mechanical ventilation for 4 weeks. Resection of the right side was unable to be performed. Two months after the second resection, she presented with chest fullness in the left breast area, and a CT scan showed a $10 \times 6-\mathrm{cm}$ left chest wall mass with

*Gore-Tex patch, registered trademark of W. L. Gore \& Associates, Inc, Newark, Del. 